\title{
skirt, cap and gown \\ How Fair are Universities to \\ Young Women in Postgraduate Study? TARA BRABAzoN
}

I did not intend to write this paper. But during the working days spent reading for what I thought would be a scholarly_but abstract—discussion of women in universities, the topic became more personal. One of the tasks—and joys —of academic life is to supervise doctoral candidates. It is one of the most stressful of our scholarly roles, combining leadership, mentoring, local knowledge and international standards. Most of my PhD students have been young women, whom I have tried to give as many opportunities as possible, to make their passage through the academy easier than my own. I have failed. It has been much tougher for them.

A few months ago, I had lunch with one of my ex-students: the first woman who gained a PhD through my supervision. I asked her about employment prospects. She reported-in her customarily deadpan fashion-that she held three jobs. One day a week, she drives a forklift truck. Two days a week, she teaches communication and cultural studies to international students. The final two days a week, she teaches English and literacy skills to unemployed Indigenous men, who are (primarily) being instructed in carpentry and woodwork. I was shocked by her words, and the consequences of them. She had spent the last ten years of her life building an academic career. These hopes now appeared lost. In this first Provocations section for Cultural Studies Review, my paper juts out from her story and investigates the costs of such a working life. If democratisation in the tertiary sector is to be taken seriously, then we must carefully survey how previously disadvantaged groups are incorporated into higher education. In response to the words of my ex-postgraduate, I sent emailed questions to my six female doctoral students. Their testimony was then labelled 'A' through to ' $F$ ' to 
connote the seniority of their candidature. I then pleated their answers against DEST surveys of the Australian academy and theoretical/historical approaches to the university's purpose. Via this approach, the attitudes of my students wedge the page, providing an intervention in the calm facade of DEST documents stressing science, training and vocationalism. I have presented their views in their own words — rather than through paraphrasing — to reveal attitudes and anger, feelings and frustrations. We do not hear-let alone read-the experiences of postgraduates in sufficient depth. When presented in this way, different approaches to the postgraduate journey are revealed that are distinct from the imperatives of completion rates, supervisory training and professional competencies.

This paper is situated in the continuing dialogue between cultural studies and education. A recent edition of the International Journal of Cultural Studies suggests that 'while cultural studies has been valorised for its insights into everyday life and the ordinary culture of various social groups, it tends to shy away from any coherent, explicit analysis of its own daily practices'. ${ }^{1}$ While such a statement may have merit internationally, it denies the strong work completed by Australian cultural studies practitioners in curriculum and policy. How we monitor and manage the educational future of postgraduate education is a point of debate and dialogue, necessitating attention to international standards of regulation and examination, national funding policies, and local teaching strategies.

\section{- Probing the Patriarchy}

People have this fantasy (as I did when I was young) of colleges being liberatory institutions, when in fact they're so much like every other institution in our culture in terms of repression and containment-so now I feel like I'm trying to break out.

bell hooks ${ }^{2}$

In most workplaces, feminist interventions are about as likely as finding John Howard crawling over sweating bodies in a mosh pit. Universities are no different. Women have remained locked in the lower levels of the academy in traditionally female disciplines and paradigms such as cultural studies. They exist on the edges of the full-time, tenured workforce. The consequences of this economically (rationalist) reality on my postgraduates are wide ranging. The completed student (A) confirmed the volatile nature of the workplace. The student who does not hold a scholarship (C) — and has paid her way through a completed PhD—was also immersed in this transitory and sessional academic workforce. The other students, who hold a scholarship, have been far less exposed to the university employment sector than $\mathrm{A}$ and $\mathrm{C}$. 


\section{What part- or full-time work do you currently undertake?}

A Three companies currently employ me in a part-time/casual/sessional manner. I am a sessional employee for —_. I am the Mass Communication (cultural studies and film studies foundational units) course coordinator. My part-time position, as Academic Facilitator, is based in Fremantle. Here I am employed as the coordinator, facilitator and administrator of the academic curriculum for the Aboriginal Boat Building course. Casually, a mineral sands mining company, employs me as an industrial representative at their bulk port facilities.

B None, but I have done various part-time tutoring jobs throughout the candidature.

C I am a lecturer at the — where I teach three units: Communications 1 and 2, and Introduction to Media and Communication. I am also a tutor at Murdoch University, at various times moving through internal, external and online modes in Introduction to Cultural Studies, and Cultural Difference and Diversity. I am also a dance teacher in the evenings.

D I work Saturdays at an antique bookshop (eight hours). I tutor during university semester, of which hours vary. I also write a column for a street press newspaper every fortnight, and an article for a screen-printing trade journal every three months.

E Part-time tutoring - at university and privately.

F Part-time-clarinet teacher and some volunteer work.

A scholarship makes a profound difference to the employment postgraduate students undertake during their candidature. The scholarship renders paid employment secondary to completing their thesis. For A and C, they undertake work to pay bills. Both hold three part-time jobs. From this basis, I asked the students about employment expectations at the submission of their thesis. All these women, except F, expressed a desire to enter the academy. They lacked specific knowledge about what this job would entail, or the process of attaining this type of employment. I then asked a follow-up question about how they assessed their current prospects.

\section{Now, what do you think your occupation will be at the conclusion of your thesis?}

A I have struggled over the past year to gain a full-time position-hence the position I now find myself in of working three varying positions. As such, in order to be financially secure I have enrolled in the CELTA (Cambridge English Language Teaching Award) course. In three months I will have completed this part-time course and have a far better chance of securing consistent employment. It would seem then, that I am 
leaning towards an occupation where I can be a facilitator/teacher. I am disappointed that I cannot find a research position to utilise and further my information-gathering skills, but I realise that through my own individual administration these skills are of great benefit and comfort.

B I still hope it will be one of the above. My first preference is to be an academic.

C I think I will be extremely lucky to walk into an academic job. Now I am unsure if I even really want a lecturing position. I have been teaching for five years and have been exhausted by the constant pressure of a teaching environment that has been taken out of my control. The increasing economic rationalist approach taken towards education in recent years has enabled the development of institutions ... that enrol full-fee paying international students. However, the mentality that accompanies this institution can be worrying.

D I realised after a year into my $\mathrm{PhD}$ that I did not have a great interest in the academy. However, I am also feeling ambiguous about entering the corporate workforce. I tested my interest in office work by taking a work-experience position in a public relations department during a summer break. I found the experience monotonous, unchallenging and I was especially wary of the office politics among the employees. My uncertainty of a singular future occupation still remains.

E Most likely an academic (writer, film theorist perhaps)—though I am not completely sure what that will be exactly.

F Still not sure, probably want to study more.

These answers are upsetting: it is always crushing when idealism is lost or decentred. I remain particularly concerned by the answers of A and C. A has always shown an interest and capability with research, but she has realised that job prospects will be in teaching. Ten years ago, she would have held an A-level lecturing position-requiring mainly teaching, but with the possibility of some research. Now this stepping-stone position is rare. Conversely, $\mathrm{C}$ has been burnt out by low-level teaching. She stated:

I must also teach over a four-hour time frame, where most university units occupy less contact hours. I find it a struggle to maintain energy throughout this period and it results in short cuts in teaching where I do not engage in so much debate in the classroom-simply because it is tiring and I must teach for the remainder of the day, I am more inclined to be quick-tempered in the classroom. As a result, I am tired after four years teaching at this institution. If I never taught another day in my life, I would not be too concerned. 
This young woman is a remarkable teacher-conscientious and eager. When she teaches in my courses, students applaud her enthusiasm, intelligence and innovation. Yet the hours of casualised, corporatised education have taken their toll on her and her future. After this question, I asked the young women about their outlook for the future.

\section{Are you optimistic or pessimistic about your career and future? Why?}

A I completed my thesis just over a year ago and have applied for five full-time academic positions in the Perth metro area (twelve nationally) and only once have I been shortlisted. I learnt that after that interview-as is the case with open and visible employment practices - that the position had already been awarded (before the interviews) and that the department in question was going through the motions to ensure that they met their legal obligations. This has made me pessimistic about the academic community here in Western Australia. I am not pessimistic about my career because I know that I have not sat down and relied on only my PhD to get me through - I am able to see the value of the qualification and adapt the skills that I have learnt into other areas. Therefore, I feel that my career is not based in one area, but spread across many. I am the epitome of the modern multiskilled woman-I am a veritable Swiss army knife!!!

B Both. I am optimistic because I am looking forward to the next step. I look forward to the sense of satisfaction that getting the $\mathrm{PhD}$ will provide and to starting on something new. I am pessimistic because I know I am entering a competitive job market and the academic position I could have expected even fifteen years ago is no longer there. I realise there may be a time of unemployment or casual employment before I find a suitable full-time job.

C I am disheartened. I have no illusions about my abilities as an academic. However, I did see it as a space in which I could live out my small life and actually make a contribution to a better world. Now that it appears that working in this field is slipping out of touch, I am confused about what to do.

D I am definitely optimistic about my career and future. I am a great believer in attaining goals if the effort is made. I intend to make a very big effort, both in realising what it is I want to do, and also in getting the job I want.

E Both. With the job market being as bad as it is, there is always the possibility of not being able to find a job suitable to my degree. However, I think the optimistic side in me believes that with a fervent interest in my area, I will at least be able to forge an opportunity and position for myself. 
F Optimistic! I think if you work hard, are committed and do whatever it takes (and I plan to) you can accomplish whatever you want to in life.

The women that the scholarship system has 'shielded' from the ruthlessly corrosive temporary workforce are more optimistic. $\mathrm{C}$ and $\mathrm{A}$ have been exposed to its full force, and offer astoundingly pessimistic testimony. A is a tough woman, standing up for her rights and mouthing the multiskilling of the age. $\mathrm{C}$ is beaten by the system: she is left pondering the foundations of academic life. D and F are self-starters, deep believers in meritocracy, while B and E are ambivalent. A and C confirm though, that talent, hard work and commitment are simply not enough. It is also significant to note that all these women have attained first-class honours, except $C$, who already holds a master's degree. These are intelligent women, already successful in the university system and its standards.

With market forces and neo-liberal policies battering the door of the Senate chambers, higher education is suffering a crisis of purpose. While there is much talk of efficiency and productivity, fewer staff are completing much more work. The women at the lower end of the seniority spectrum are not only the most vulnerable, but are undertaking the most teaching in overcrowded and under-resourced classrooms. ${ }^{3}$ Teaching at this level has always been tough, but it is worse now than when I moved countries to attain my first full-time academic job. This position was a one-year appointment in New Zealand-attained at short notice to temporarily replace a male lecturer who won a research fellowship. The university did not pay to move me, or pay my airfare for the return to Australia. I was merely expected to arrive and lecture to three hundred first-year history students. I swum, but I often felt as if I was sinking. My second position upon returning to Australia was as an A-level lecturer. Once more, I was expected to arrive and teach three separate courses. The week before I commenced teaching, another course was added to my teaching load. On my appointment, I was promised that a rise to tenure and a B-level appointment would be rapid. That promotion never materialised. Lesson learnt about academic promises. After eighteen months in this job, I moved once more-this time for a safe, tenured B-level appointment. The point of this story is that if I had not risked my entire professional life three times in those first three years, I would not be in a full-time position. I (literally) had to move countries to attain work. But I was given opportunities. For my current PhD students, these chances do not exist. Yearlong appointments are not made. Casual staff are employed to teach one course, for one semester. Female postgraduate students are particularly vulnerable to this situation. Ponder these statistics from DEST: 
FTE for full-time, fractional full-time and estimated casual staff by work contract, 1996-2001

\begin{tabular}{cccccccc}
\hline & \multicolumn{2}{c}{ Full-time } & \multicolumn{2}{c}{ Fractional full-time } & \multicolumn{2}{c}{ Estimated Casual } & Total \\
\hline Year & FTE & $\begin{array}{l}\text { Percentage } \\
\text { change on } \\
\text { prioryear }\end{array}$ & FTE & $\begin{array}{l}\text { Percentage } \\
\text { change on } \\
\text { prioryear }\end{array}$ & FTE & $\begin{array}{c}\text { Percentage } \\
\text { change on } \\
\text { prioryear }\end{array}$ \\
\hline 1996 & 65,254 & 1.4 & 7,449 & 4.1 & 10,185 & 10.1 & 82,888 \\
1997 & 62,771 & -3.8 & 7,910 & 6.2 & 10,723 & 5.3 & 81,404 \\
1998 & 61,284 & -2.4 & 8,290 & 4.8 & 10,711 & -0.1 & 80,285 \\
1999 & 61,192 & -0.2 & 8,059 & -2.8 & 11,580 & 8.1 & 80,832 \\
2000 & 61,568 & 0.6 & 7,973 & -1.1 & 12,760 & 10.2 & 82,301 \\
2001 & 61,732 & 0.3 & 8,916 & 11.8 & 13,162 & 3.2 & 83,809 \\
\hline
\end{tabular}

Source: Staff 2001: Selected Higher Education Statistics, Commonwealth Department of Education Science and Training, Commonwealth of Australia, 2002, DEST No. 6836.HERC 02A

This is a remarkable table. It demonstrates the casualisation of the workforce in the last six years, and a decline in the full-time workforce. There are more casual positions available, but a sluggish 'growth' in the permanent sector. For Murdoch University, in which all the women have gained or are attaining their $\mathrm{PhD}$, the statistics for women, men, tenure and contract positions are even more disturbing.

Number of full-time and fractional full-time staff by state, institution, work contract and gender, 2001-Murdoch University

\begin{tabular}{lcc}
\hline & Men & Women \\
\hline Full-time & 523 & 422 \\
Fractional full-time & 60 & 205 \\
\hline
\end{tabular}

Source: Staff 2001: Selected Higher Education Statistics, Commonwealth Department of Education Science and Training, Commonwealth of Australia, 2002, DEST No. 6836.HERC 02A

Murdoch University has humanities and education programs, alongside the conventional sciences and veterinary training. Despite these female-dominated areas, more women than men are placed in limited and fractional term contracts. The consequences for research and building an academic career are profound. Therefore, my students have merely been swept up into the trends of the university encircling them. 
Competence is determined by the environment. Strong performance is encouraged and framed by an appropriate context. Women are outside leadership positions at universities because their activities are frequently invisible, and their modalities of power are distinct from the organisational culture of the workplace. Women's lives in the corporate and public sector make more sense when conceding that managers see a woman first, and a worker second. Throughout history, women who speak with authority and knowledge have either been labelled witches or hysterics. Such determinations have been particularly marked in Australia's history, with its highly segregated workforce. ${ }^{4}$ To make this point clear for the university sector, consider these results from the government survey of Murdoch University's staff in 2001:

Number of full-time and fractional full-time staff by state, institution, current duties classification and gender, 2001-Murdoch University

\begin{tabular}{lccccc}
\hline & $\begin{array}{l}\text { Above senior } \\
\text { lecturer }\end{array}$ & $\begin{array}{c}\text { Senior lecturer } \\
\text { (level C) }\end{array}$ & $\begin{array}{c}\text { Lecturer } \\
\text { (Level B) }\end{array}$ & $\begin{array}{c}\text { Below Lecturer } \\
\text { (Level A) }\end{array}$ & $\begin{array}{c}\text { Total: Academic } \\
\text { Classifications }\end{array}$ \\
\hline Men & 104 & 88 & 80 & 32 & 304 \\
Women & 11 & 36 & 83 & 52 & 182 \\
\hline
\end{tabular}

Source: Staff 2001: Selected Higher Education Statistics, Commonwealth Department of Education Science and Training, Commonwealth of Australia, 2002, DEST No. 6836.HERC 02A

My concern is what postgraduate students are learning about the academy when walking around the corridors of the university. This is not a problem of a single institution. The percentages for the entire university sector in Australia are similarly disturbing.

Number of full-time and fractional full-time staff by state, institution, current duties classification and gender, 2001-National Percentage

\begin{tabular}{lccccc}
\hline Percentage & $\begin{array}{l}\text { Above senior } \\
\text { lecturer }\end{array}$ & $\begin{array}{c}\text { Senior Lecturer } \\
\text { (Level C) }\end{array}$ & $\begin{array}{l}\text { Lecturer } \\
\text { (Level B) }\end{array}$ & $\begin{array}{c}\text { Below Lecturer } \\
\text { (Level A) }\end{array}$ & $\begin{array}{c}\text { Total: Academic } \\
\text { classifications }\end{array}$ \\
\hline Men & 15.3 & 15.2 & 16.5 & 7.7 & 54.8 \\
Women & 3 & 6.4 & 13.2 & 8.7 & 31.3
\end{tabular}

Source: Staff 2001: Selected Higher Education Statistics, Commonwealth Department of Education Science and Training, Commonwealth of Australia, 2002, DEST No. 6836.HERC 02A

Forty years after the explosion of second-wave feminism, only three per cent of Australian university staff is made up of female (associate) professors. This has been no great victory for feminism. The task now is to attempt to make the situation better for the next generation of students. 
There is a confluence of professionalism and maleness. This means that the subjectivity of female teachers and students is frequently displaced or dismissed. One goal of this Provocations paper was to attach postgraduate voices to the DEST statistics, to recognise how 'our' current problems are being passed on to the next cohort of academics. To attain social justice requires more than an expression of disappointment or despair, but intervention. Men have held power and authority throughout the history of universities. The aim for the current generation who are just entering positions of leadership is to naturalise the work of women, not justify it. I am concerned by the gentle, quiet acceptance by women that they will earn less, that they are not worthy of promotion and are not management material. Much of this discourse is framed by the presentation of gender within teacher education textbooks. Karen Zittleman and David Sadker assessed twenty-three teacher education textbooks published between 1998 and 2001. They discovered that methodology books featured little more than one per cent of their content confronting gender issues. ${ }^{5}$ This gendered information gap re-states an expectation that women will be under-represented in management and leadership positions. With such an absence in education-a field where women have made a historically wide-ranging contribution-it is no surprise that universities perpetuate this bias. The silent tragedies of women who we train remain unrecognised and addressed.

The questions I distributed to my students produced (perhaps) predictable results. The young women who were either finished or nearly completed their thesis had encountered the most sexism. The two students who had just started their studies had found little to concern them. In other words, the more students were immersed in the system, the greater the observed inequalities.

\section{Do you think that being a woman will impact/has impacted on your ability to attain an academic career?}

A I am a little wary of saying outright-YES! Because I do not want it to seem that I believe that because I am a woman is the only reason that I cannot get a position as a lecturer in Australia. I am certainly not a victim of my gender, but I know that my gender is a victim of a testosterone-entrenched system. Having said this, I believe that there are far too many 'boys' networks that exist in the academic hallways. I know of a particular example where a man was in consistent employment in Australian universities, even though he had not completed his PhD. He applied for jobs where the minimum requirement was a $\mathrm{PhD}$, but he was still short-listed and gained a position as a B-level lecturer. It was part of his contract to complete his PhD in the six months before he started his active duty (he was paid to do so) and I don't think he did. In fact I know that I gained my PhD before he did and it still grates me to think that because he had a 'boys' network membership he was able to slip his way into these positions. I 
also believe that there are not enough women given the chance in Australian universities-I know that when I walk the hallways at Murdoch there are not enough academic women's names on the doors and this upsets me.

B Yes. I fear that it will mean I will be doing casual work instead of obtaining a full-time position.

C Absolutely. Academic institutions are peppered with men in positions of power who appoint more men to academic positions. Women are administrators, librarians, tutors and personal assistants. I have been dealt with in a range of condescending ways throughout my teaching career. I am expected to do the crap jobs and not complain about being ripped off. I do believe that being a woman will significantly incapacitate my ability to obtain an academic appointment. Men slip easily into these positions while women must fight for them.

D Not so far as writing a PhD and tutoring students. If I were to get into a full-time teaching academic career, I don't think my gender will have much of an impact. The department in which I am studying, the humanities, is female dominated compared to other parts of the university and appears supportive of women's concerns. My only worry would concern the upper echelons of administrative power within the university structure. The maintenance of patriarchal ideology is much more concentrated there and if I were to enter the academy, I would be more interested in aiming for these positions than teaching ones.

E No.

F I don't think it has so far and I'm not sure about the future.

The difference in attitude between the students is startling. A-rightly-was angry that men in her circle have gained appointments not available to her, even though she has a doctorate. Similarly C was simply expected to do 'the crap jobs' because she is a woman. B-a specialist in feminist cultural studies-recognised the casualisation of work in her immediate future. $\mathrm{D}$, who is investigating the World Wide Web as her doctoral topic, affirmed that women are expected to teach, but entering administration (where she has expertise) will be more difficult. Ironically—but perhaps not—my two students who have recently joined the program had no experience of inequality.

\section{- Lost to a SYSTEM}

Those of us who believe in educational social justice within and outside cultural studies need to monitor women's role in universities. The tertiary sector-like the economy generallyhas fractured into a dual labour market: permanent, well-trained workers with high wages and good conditions, and insecure, low-paid, poorly trained and expendable workers. Fur- 
ther, the Australian workforce is highly segregated in terms of gender-far more than the United States or the United Kingdom. Through much of Australia's history, men have been paid a 'family wage', which resulted in women earning fifty-four per cent of the male rate. ${ }^{6}$ Historically, during difficult economic periods, such as the 1930s and the reconstruction of the early 1950s, women's employment rate stagnates more than men's. Yvonne Search believed that 'the woman who wishes to succeed as leader and manager in higher education needs to develop the capacity to recognise and take advantage of the opportunities that are offered'. ${ }^{7}$ However, what if opportunities are not offered? The survey of my six students showed that simply no full-time and stable employment chances have been provided. Women are underrepresented in educational leadership, making it difficult for men to appoint a woman as a colleague when they are accustomed to seeing men in these positions. Therefore young women in particular require a 'springboard of opportunity'. ${ }^{8}$ Too many men dominate the higher echelons of education and are given employment chances not granted to women. The academy has changed, but very slowly. Also, the role and place of women in the academy has been systematically erased from history. Margrit Eichler researched the remarkable biographies of women who struggled to gain an academic career. She found that the potent work of leading female Canadian sociologists born before 1930 has simply been lost through 'a politics of gender and a politics of knowledge'. ${ }^{9}$ These women suffered through unstable part-time work, the following of their husbands to better jobs, and difficult conditions in which to complete a PhD. While some of these stresses have been reduced for contemporary women, there is an institutional sexism that saturates the laws, structures and selection criteria in the present tertiary sector.

With a decline in full-time academic staff numbers - and an increase in student intakepart-time staff must undertake unstable, casualised tutoring, which treats them as disposable fodder to and for the system. Similar tendencies to Australia are also emerging in the United Kingdom. Studies have reported that two in three research assistants, one in three lecturers, one in five senior lecturers and one in eighteen professors are female. ${ }^{10}$ Melanie Ward's study revealed that there is limited opportunity for female academics to combine work and family responsibilities. But the young women I surveyed are all under the age of thirty, unmarried and without children. Therefore, family responsibilities - in terms of childrenare not a limiting factor. Ward did not research or consider this group of young, childless women, but merely reported that 'the vast majority of the young women in our data set are research assistants on short-term contracts'. ${ }^{11}$ The reason for such a result was not specified.

Very little research has been conducted on-or with-young postgraduate women in the tertiary sector. Some investigation has been undertaken on the experiences of mature-aged female students. Through the 1980s, there was not only more women entering the workforce, but increased involvement of mature-aged women in tertiary studies. Reports have 
demonstrated that these women have shown both a higher academic performance and motivation than other groups. But as researchers have realised, these judgments are based on a 'subjective assessment of their performance'. ${ }^{12}$ What are the consequences of such expectations (and ideologies) on young women, particularly at postgraduate level?

\section{What role does age play in the attainment of an academic career?}

A I believe that the removal of the 'apprentice' level-A-level lectureships-is having a detrimental effect on academic culture. I was twenty-six when I completed my PhD and I often felt that my age was problematic. I know that the A level is not the best position, but I knew that if I was offered one I would take it and serve my time in order to gain the experience to play the game and administer my work. The removal of this level has forced younger academics to compete with academics with more experience-it is not a level playing field in either generation or gender. I find this deliciously ironic when universities are seen as the incubators of social justice and change. It appears to me now that universities often represent wider community beliefs and are not the critical reflectors that I once believed.

B I am not sure.

C I think it plays a very large role. Though I do think it is more of a problem for young women than young men. A young man in academia is taken more seriously. Young men are outfitted for their academic life from the moment they enrol in higher degree work. Young women, however, are treated as part-time academics who do higher degree work on their way to an administrative job or, more appropriately, to a husband and a baby. A number of my female friends have been treated radically differently to men in the academic world. A very close dear friend of mine who does not even have a master's degree (though to be fair he has wide practical and industry experience) is working as a B-level lecturer at a university. Another acquaintance, a very clever man, who has been doing his $\mathrm{PhD}$ for about eight years is working as a lecturer at a leading eastern states university. A young man who I taught in his undergraduate degree is now doing a PhD and working on book compilations for leading academics. These are all fabulous young men who are very clever-however I cannot give you comparative stories for the women academics I know. They are teaching primarily at tutorial level.

D Age is an important factor in any career. For me (as a twenty-four year old), youth is a disadvantage as people tend to look at you as inexperienced and therefore lacking in certain skills. However, I think that if someone has the necessary cultural capital, theoretical knowledge and vocabulary to interact intelligently with their academic colleagues, it shouldn't pose too great a problem. 
E Although it is extremely biased, I do believe that the university structure favours those who are more 'mature' in age for senior positions. However, I think there will be opportunities for people, regardless of age, for less senior positions.

F I'm not sure.

There is some powerful work to be done in this area. While research has explored the role of mature-aged women in the tertiary sector, it seems that young women have been the neglected group. I certainly have an understanding of their plight. I started tutoring at twentyone years of age, and was younger than many of my students. I have been in full-time lecturing positions since the age of twenty-four. A decade later, I attend meetings each day with men who are nearly double my age. I have been called 'girly' at a meeting. While gender can be tracked by statistical tables, the consequence of age-based discrimination on young women requires more systematic work than the current data or theoretical material makes possible. Like B and F both replied, I'm not sure. We all remain unsure about what happens to young women after postgraduate training. Young women are attaining a doctorate during the period when such a qualification is starting to mean less. As James Ottavio Castagnera reported, 'in current searches for college presidents, it seems that the absence of the initials 'PhD' after the candidate's name is not necessarily an impediment if the fund-raising record is substantial'. ${ }^{13}$ Perceptions of competence are changing.

\section{- Educating the elites?}

Many historiographical debates about education focus on the democratisation and attendant elitism of the university system. The Renaissance ideals of the university framed education as preparation for gentlemanly status. The purpose of education- to either gain social mobility or reinforce already existing power structures_places young women in a difficult position. The confluence between class and gender raises questions about who attends university, why, and what happens to them. The increasing participation of women has resulted in some unexpected consequences. Massification, managerialism and marketisation have increased the pressures on academics as a labour force. Calls for democracy and meritocracy are not enough to shake the patriarchal foundation of the educational system. As the Birmingham Centre for Contemporary Cultural Studies scholars realised in the early 1980s, 'access is not enough'. ${ }^{14}$ Their analysis is confirmed by the status of educated young women. They may have been granted access to PhD programs, but their expertise and energies are unwanted except as temporary tutors. Grant Harman, in assessing Australia's higher education system in the early 1990s after the Dawkins reforms, stated that the aim is to 'ensure that higher education institutions more closely serve national economic needs'. ${ }^{15}$ Currently, the Howard 
government, through 'family policies' and tax credits, is emphasising the role of young women as mothers, not workers. The lack of paid maternity leave demonstrates the incapacity of Australian political figures to link the roles of mother and worker. The restructuring of universities since the Labor years, the ageing academic workforce, the overcrowded 'multiversity', and the reliance on private funding have all conflated at the worst time for young women.

Transforming an elite model of education into a popular system has been a difficult process. Besides qualitative and quantitative concerns, we must ask how much growth in access to higher education is necessary for Australia's economic and social structures. Is the purpose of tertiary education to train women for an academic or public function for which there is currently little calling? With degree inflation and the current state of the sector, there is now a danger of over-education. Young women have their expectations raised, and then hopes crushed. In an era of professionalism, credentialing and specialisation, there are simply too many well-educated, bright and articulate young women.

Feminist pedagogies are meant to disrupt a liberal curriculum. In a neo-liberal environment, such interventions are more difficult. Jane Rinehart has realised that 'we live in hard times_-hard for feminists, hard for educators, even harder for feminist educators'. ${ }^{16}$ We need to grasp the structures of oppression, and challenge the corroding normative criteria that are displacing a generation of young female scholars. I am tired of a specific group of feminists describing the easy ride of Generation X feminists in the academy. For example, Carmen Luke has stated (in 1999_which makes her judgment even more concerning):

Part of the generational diaspora is evident in the university sector where senior women have fought long and hard to get to the position they now hold. Young women coming up through the ranks of academia do not have to fight the same battle that feminists engaged in 20 years ago. ${ }^{17}$

Luke is correct: young women do not have to fight the same battles. The environment is currently tougher and more insidious. Young women are not even being granted the opportunity to fight 'long and hard', but are dismissed by a system that does not need them. Luke's rendering does not grasp the current (and specific) challenges faced by young women encircling university positions with their nose pressed up against the window pane of full-time employment. What is to become of these articulate, funny, committed and high-achieving women? So far, the provisional result is in: the system has failed them.

TARA BRABAzON teaches in the School of Media, Communication and Culture, Murdoch University. 
1. K. Maton and H. Wright, 'Returning Cultural Studies to Education,' International Journal of Cultural Studies, vol. 5, no. 4, p. 383.

2. bell hooks, in Andrea Juno and V. Vale (eds), Angry Women, RE/Search Publications, New York, 1999 , p. 89

3. For a discussion of the changing relationships between gender, teaching and research, see Alison Lee and Bill Green, 'Pedagogy and Disciplinarity in the "New University", UTS Review, vol. 3, no. 1, May 1997, pp. 1-25.

4. Susan Faludi reported that 'Australia has a highly segregated workforce: in 191184 per cent of female labour worked in disproportionately female occupations, and by 1984 the figure, at 82 per cent, had barely changed'. Backlash, Chatto and Windus, London, 1991, p. 398.

5. Karen Zittleman and David Sadker, 'Gender Bias in Teacher Education Texts: New (and Old) Lessons', Journal of Teacher Education, vol. 53, no. 2, March-April 2002, p. 168.

6. J. Currie, G. Bossinga, C. Baldock and D. Mulligan, 'Now Opportunities for Women? Tertiary Graduates and the Labour Market with Special Emphasis on the Experiences of Mature Age Women', report no. 4, Studies in the Sociology of Work, School of Education and Social Inquiry, Murdoch University, June 1986, p. 2.

7. Yvonne Search, 'Outside Academia: The Changing Job Market and its Influence', in H. Eggins (ed.), Women as Readers and Managers in Higher Education, Open University Press, Buckingham, 1997 , p. 34
8. J. Powney, 'On Becoming and Being a Manager in Education', in Eggins, p. 61.

9. Margrit Eichler, 'Women Pioneers in Canadian Sociology: The Effects of a Politics of Gender and a Politics of Knowledge', Canadian Journal of Sociology, vol. 26, no. 3, 2001, p. 376.

10. Melanie Ward, 'The Gender Salary Gap in British Academia', Applied Economics, vol. 33, no. 13, October 20, 2001.

11. Ward.

12. J. Currie, C. Baldock, G. Bossinga and H. Pears, 'Tertiary Experiences', report no. 2, Studies in the Sociology of Work, School of Education and Social Inquiry, Murdoch University, July 1988, p. 101.

13. James Castagnera, 'The Role of Higher Education in the Twenty-first Century: Collaborator or Counterweight?', Change, September-October 2001 , p. 42.

14. Centre for Contemporary Cultural Studies, Unpopular Education: Schooling and Social Democracy in England since 1944, Hutchinson, London, 1981, p. 263.

15. Grant Harman, International Higher Education, Garland Publishing, 1991, p. 593.

16. Jane Rinehart, 'Feminist Wolves in Sheep's Disguise: Learning Communities and Internships', in M. Mayberry and E. Rose (eds), Meeting the Challenge: Innovative Feminist Pedagogies in Action, Routledge, New York, 1999, p. 64.

17. Carman Luke, 'Feminism in New Times', in L. Christian-Smith and K. Kellor (ed.), Everyday Knowledge and Uncommon Truths: Women in the Academy, Westview Press, Boulder 1999, p. 6. 